\title{
Accumulation of Mitochondrial DNA Microsatellite Instability in Malaysian Patients with Primary Central Nervous System Tumors
}

\author{
Siti Muslihah ABD RADZAK, Siti Zulaikha Nashwa MOHD KHAIR, Farizan AHMAD, Zamzuri IDRIS, \\ Abdul Aziz MOHAMED YUSOFF \\ Sains Malaysia University, School of Medical Sciences, Health Campus, Department of Neurosciences, 16150 Kubang Kerian, Kelantan, \\ Malaysia
}

Corresponding author: Abdul Aziz MOHAMED YUSOFF azizmdy@yahoo.com

\section{ABSTRACT}

AIM: To determine the mitochondrial microsatellite instability (mtMSI) status in a series of Malaysian patients with brain tumors. Furthermore, we analyzed whether the mtMSI status is associated with the clinicopathological features of the patients.

MATERIAL and METHODS: Forty fresh frozen tumor tissues along with blood samples of brain tumor patients were analyzed for mtMSI by PCR amplification of genomic DNAs, and the amplicons were directly sequenced in both directions using Sanger sequencing.

RESULTS: Microsatellite analysis revealed that $20 \%$ (8 out of 40) of the tumors were mtMSI positive with a total of 8 mtMSI changes. All mtMSI markers were detected in D310 and D16184 of the D-loop region. Additionally, no significant association was observed between mtMSI status and clinicopathological features.

CONCLUSION: The variations, specifically the mtMSI, suggest that the mitochondrial DNA (mtDNA) can be targeted for genomic alteration in brain tumors. Therefore, the specific role of mtDNA alteration in brain tumor development and prognosis requires further investigation.

KEYWORDS: Mitochondrial microsatellite instability, D loop, brain tumor, Malaysian patients

\section{INTRODUCTION}

O entral nervous system (CNS) tumors account for about $15 \%$ to $20 \%$ of all malignancies existing in childhood and adolescence. Approximately $90 \%$ of all CNS tumors are brain tumors, with the reminder occurring in the spinal cord and cranial nerves (21). However, the molecular mechanisms underlying brain tumorigenesis are still not completely defined or understood. It is believed that the accumulation of genetic alterations, such as mutations in proto-oncogenes and tumor suppressor genes, plays a vital role in the progression of brain tumors $(7,45)$.
Genomic instability is considered to be responsible for an increased tendency of mutations and the promotion of further DNA alterations, thus being the hallmark of cancer initiation and progression. Elucidating the role of genomic instability in tumorigenesis is believed to pave the way for understanding cancer (42).

Microsatellites are well-recognized as short tandem repeats (STRs) or simple sequence repeats (SSRs) of DNA comprising 1-6 base pairs (24). These simple repetitive nucleotide motifs widely appear all over the genome and are susceptible to
Siti Muslihah ABD RADZAK

(1) : 0000-0003-0009-1478

Siti Zulaikha Nashwa MOHD KHAIR (1) : 0000-0001-7516-2045

Farizan AHMAD
(1) : 0000-0001-6413-7530 
polymorphic changes among individuals (24). Accumulation of mutations are derived from either insertions or deletions (indels) in some repetitive sequences of microsatellites, which can cause a condition called microsatellite instability (MSI) (5). It has been shown that MSI can be triggered by a defective DNA mismatch repair system, which leads to an inability to fix errors in repetitive DNA sequences that occur during DNA replication $(5,13)$. The first report of MSI contributing to human cancer was published in 1993, describing $28 \%$ of MSI in colon tumors examined (61). Since then, the role of MSI has been discovered in many different types of cancer $(9,11,32,56,65)$. However, instability in mitochondrial DNA (mtDNA) is still insufficiently characterized and is not well studied. mtDNA is referred to as the second human genome, the alterations of which are believed to contribute to carcinogenesis in human.

Mitochondria are known for their pivotal roles in generating ATP via aerobic respiration, reactive oxygen species (ROS) production, fatty acid oxidation, and programmed cell death. Each mitochondrion contains its own 16,569 bp circular DNA, which encodes 37 genes for 13 subunits of electron transport chain complexes (I, III, IV, and V), 22 tRNAs and 2 rRNAs (1). mtDNA also comprises a non-coding region called the displacement loop (D-loop) that is responsible for the modulation of mitochondrial genome replication and transcription (2).

mtDNA alterations in the form of point mutations, deletions, insertions, copy number changes and MSI, are believed to be hotspots of cancer research. Such genetic alterations in mtDNA have been widely reported in various human cancers $(22,35-37,47,62,63,67)$. Our previous studies have discovered a high frequency of somatic mtDNA mutations in brain tumor patients (46).

Although some studies have reported the occurrences of mitochondrial microsatellite instability (mtMSI) in multiple cancer types $(8,10,16,33,38,64,68)$, thus far no published studies have directly investigated the role of $\mathrm{mtMSI}$ in brain tumorigenesis. Therefore, this study was designed to determine the role of $\mathrm{mtMSI}$ in brain tumors among Malaysian patients.

\section{MATERIAL and METHODS}

\section{Patients and Tumor Samples}

A total of 40 Malay patients with brain tumor cases, who diagnosed at the Department of Neurosciences, Universiti Sains Malaysia, Kelantan from October 2017 to February 2012, were included in this study. The study was approved by the research ethics committee of Universiti Sains Malaysia. Informed consent was obtained from each participating patient. All tumors were reviewed by at least two neuropathologists and confirmed to meet the World Health Organization (WHO) diagnostic criteria for the brain tumors classification (46). The tumor series included 4 astrocytomas WHO grade I (A I), 6 astrocytomas WHO grade II (A II), 4 anaplastic astrocytomas WHO grade III (AA III), 8 glioblastomas WHO grade IV (GBM), 16 meningiomas WHO grade I (M I) and 2 atypical meningiomas WHO grade II (M II). Twenty paraffin-embedded archival post-mortem human brain tissue from traffic accident victims with morphologically confirmed normal brain tissues served as controls. The DNAs were extracted from all samples using the QIAamp DNA Mini Kit (QIAGEN, Hilden, Germany) according to the manufacturer's instructions.

\section{mtMSI Analysis}

MSI in mtDNA was analyzed in genomic DNAs (isolated from tumor tissue and blood sample patients) that need amplification of the mtDNA fragments by PCR and then direct sequencing of amplicons using Sanger sequencing. Briefly, 12 sets of primers were used as described previously (68) to amplify the mtDNA fragments. PCR amplification was performed in the SureCycler 8800 Thermal Cycler (Agilent Technologies, Inc., Santa Clara, CA, USA) with PCR conditions as follows: initial denaturation at $98^{\circ} \mathrm{C}$ for $30 \mathrm{sec}$ followed by 28 cycles of denaturation at $98^{\circ} \mathrm{C}$ for $10 \mathrm{sec}$, annealing at $58^{\circ} \mathrm{C}$ for $30 \mathrm{sec}$, elongation at $72^{\circ} \mathrm{C}$ for $1 \mathrm{~min}$ and a final elongation step at $72^{\circ} \mathrm{C}$ for 2 min. Purified PCR products were sequenced in both directions using the same primers used for PCR amplification. The sequencing was carried out using the BigDye® Terminator v3.1 cycle sequencing kit (Applied Biosystems, Foster City, CA, USA) on an ABI Prism 3700 DNA Analyzer automated sequencer (Applied Biosystems, Foster City, CA, USA). Electropherogram results were aligned using BLAST software from the NCBI site (http://www.ncbi.nlm. nih.gov/blast) and then compared with the published revised Cambridge Reference Sequence (rCRS) of the human mtDNA (NC_012920) in the MITOMAP database (www.mitomap.org).

\section{Statistical Analysis}

Statistical data were performed using IBM SPSS Statistics for Windows, version 24 (IBM Corp., Armonk, N.Y., USA). The relationship between mtMSI status and clinicopathological parameters was analyzed using Chi-square or Fisher Exact test. P-values of $<0.05$ were considered as statistically significant.

\section{RESULTS}

Clinicopathological characteristics and their association with mtMSI status are shown in Table I. There were 20 males (50\%) and 20 females (50\%) among 40 patients included in this study, with their age at diagnosis ranging from 5 to 73 (mean: 40.6) years. Based on histological grading, 8 cases (20\%) were GBM, 6 cases (15\%) A II, 4 cases (10\%) A I, 4 cases (10\%) AA III, 16 cases (40\%) M I and 2 cases (5\%) M II. mtMSI analysis revealed that 8 out of 40 patients $(20 \%)$ had a total of 8 different alterations within two different loci of $\mathrm{mtMSI}$ markers.

Representative results of sequencing for the mtMSI analysis are shown in Figure 1A, B. Microsatellite marker alterations were observed within the D-loop region at the nucleotide positions 303-315 (D310) and 16184-16193 (D16184) (Table II). We identified one alteration, $\mathrm{C}_{5} \mathrm{TC}_{4}>\mathrm{C}_{8} \mathrm{TC}$ at 1618416193 region which has not been previously reported in the MITOMAP database. These mtMSI changes constituted the replacement of a single base $\mathrm{T}$ with $\mathrm{C}$ at position 16189 and $\mathrm{a}$ 
Table I: Clinicopathological Parameters and mtMSI Status in Brain Tumor Patients

\begin{tabular}{|c|c|c|c|c|}
\hline \multirow{2}{*}{ Parameter } & \multirow{2}{*}{$\begin{array}{c}\text { Total no. of patients, } \\
\text { n (\%) }\end{array}$} & \multicolumn{2}{|c|}{ mtMSI status (\%) } & \multirow[b]{2}{*}{$\mathbf{p}$} \\
\hline & & mtMSI positive & mtMSI negative & \\
\hline \multicolumn{5}{|l|}{ Gender } \\
\hline Male & $20(50)$ & $6(30)$ & $14(70)$ & \multirow{2}{*}{0.235} \\
\hline Female & $20(50)$ & $2(10)$ & $18(90)$ & \\
\hline \multicolumn{5}{|l|}{ Age (years) } \\
\hline$<40$ & $19(47.5)$ & $3(15.8)$ & $16(84.2)$ & \multirow{2}{*}{0.698} \\
\hline$\geq 40$ & $21(52.5)$ & $5(23.8)$ & $16(76.2)$ & \\
\hline Mean & 40.6 & & & \\
\hline Range & $\begin{array}{c}5 \text { - } 73 \text { mDNA } \\
\text { Microsatellite Instability }\end{array}$ & & & \\
\hline \multicolumn{5}{|c|}{ Tumor Type (grade) } \\
\hline Al & $4(10)$ & $1(25)$ & $3(75)$ & 0.709 \\
\hline A II & $6(15)$ & $0(0)$ & $6(100)$ & \\
\hline AA III & $4(10)$ & $1(25)$ & $3(75)$ & \\
\hline GBM & $8(20)$ & $3(37.5)$ & $5(62.5)$ & \\
\hline M I & $16(40)$ & $3(18.8)$ & 13 (81.2) & \\
\hline M II & $2(5)$ & $0(0)$ & $2(100)$ & \\
\hline
\end{tabular}

A I: Astrocytoma WHO grade I, A II: Astrocytoma WHO grade II, AA III: Anaplastic astrocytoma WHO grade III, GBM: Glioblastoma WHO grade IV, M I: Meningioma WHO grade I, M II: Atypical meningioma WHO grade II.

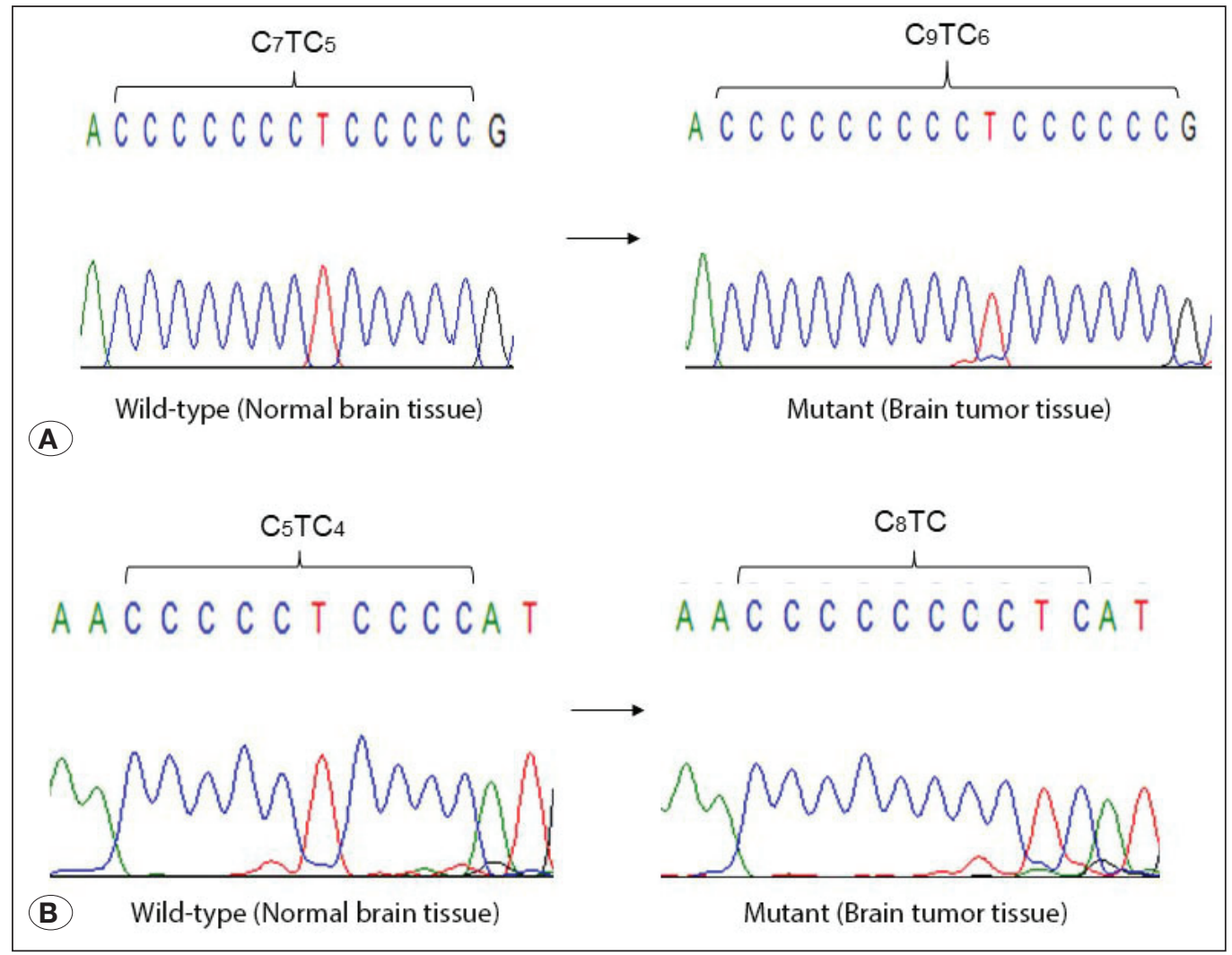

Figure 1: Representative sequencing results depicting examples of $\mathrm{mtMSI}$ changes. A) Electropherogram shows the insertions of poly $\mathrm{C}$ stretch at nucleotide position 303-315. B) mtMSI changes exhibit a single base $\mathrm{T}$ to $\mathrm{C}$ substitution at 16189 and $\mathrm{C}$ to $T$ substitution at 16192 , respectively (at 16184-16193 region). 
Table II: Details of mtMSI Changes Detected in Brain Tumor Patients

\begin{tabular}{|c|c|c|c|c|c|c|}
\hline $\begin{array}{l}\text { Nucleotide } \\
\text { changes }\end{array}$ & Region & Position & $\begin{array}{l}\text { Occurrence in } \\
\text { patients }(n=40)\end{array}$ & Histology & Novel/Reported & References \\
\hline $\mathrm{C}_{7} \mathrm{TC}_{5}>\mathrm{C}_{7} \mathrm{TC}_{6}$ & D-loop & $303-315$ & 3 & AA III, GBM & $\begin{array}{c}\text { solid tumors, colorectal, } \\
\text { ovarian }\end{array}$ & $11,33,38$ \\
\hline $\mathrm{C}_{7} \mathrm{TC}_{5}>\mathrm{C}_{8} \mathrm{TC}_{6}$ & D-loop & $303-315$ & 2 & A I, M I & $\begin{array}{c}\text { solid tumors, low grade } \\
\text { astrocytomas, colorectal, } \\
\text { ovarian }\end{array}$ & $11,25,33,38$ \\
\hline $\mathrm{C}_{7} \mathrm{TC}_{5}>\mathrm{C}_{9} \mathrm{C}_{6}$ & D-loop & $303-315$ & 1 & M I & colorectal, ovarian & 33,38 \\
\hline $\mathrm{C}_{5} \mathrm{TC}_{4}>\mathrm{C}_{8} \mathrm{TC}$ & D-loop & $16184-16193$ & 1 & GBM & - & present study \\
\hline $\mathrm{C}_{5} \mathrm{TC}_{4}>\mathrm{C}_{10}$ & D-loop & $16184-16193$ & 1 & GBM & $\begin{array}{l}\text { Leukemia, low grade } \\
\text { astrocytomas, endometrial } \\
\text { female cancer }\end{array}$ & $24,25,39,64$ \\
\hline
\end{tabular}

A I: Astrocytoma WHO grade I, AA III: Anaplastic astrocytoma WHO grade III, GBM: Glioblastoma WHO grade IV, M I: Meningioma WHO grade I

conversion of $\mathrm{C}$ to $\mathrm{T}$ at position 16192. However, no instability was found in the remaining 10 microsatellite markers screened in the patients.

In this study, the association of mtMSI status with clinicopathological parameters in patients was further evaluated (Table I). mtMSI was observed much less frequently in females $(n=2 / 20$; $10 \%$ ) than in males ( $n=6 / 20 ; 30 \%)$. However, there was no significant association between mtMSI status and sex $(p=0.235)$.

In this study, a statistically insignificant association was found between mtMSI status with $<40$ and $\geq 40$-year-old age groups $(p=0.698)$. mtMSI was more prevalent in the $\geq 40$-year-old age group $(n=5 / 21 ; 23.8 \%)$ than in the $<40$-year-old age group $(n=3 / 19 ; 15.8 \%)$.

Furthermore, there was no statistically significant difference between mtMSI status and histological types of brain tumors $(p=0.709)$. mtMSI was mostly identified in GBM $(n=6 / 16$; $37.5 \%)$ followed by A I ( $n=1 / 4 ; 25 \%)$, A III ( $n=1 / 4 ; 25 \%)$, and M I ( $n=3 / 16$;. 18.8\%). No, instability was found in A II and M II samples.

\section{DISCUSSION}

Studies on mitochondrial instability have been described in a wide variety of cancers, including colorectal, gastric, lung, breast, cervical, ovarian, and endometrial cancers $(17,32,44,53,68)$. In many cases, the incidence of mtMSI has been commonly reported in the hypervariable D-loop region, suggesting that this region may be considered a hotspot of genetic instability $(6,12,19,30,44,52,53)$. Research efforts have recently focused on the occurrences of mtMSI in the noncoding D-loop region $(3,12,31,40,52,57,61)$, with only a few studies examining the entire mitochondrial genome $(38,69)$. As described by Habano et al., mtMSI of the poly $\mathrm{C}$ stretch has been detected mostly in the D-loop region in colorectal carcinoma patients (16). In 2003, a study of gliomatosis cerebri with mitochondrial genomic instability was performed with the outcome analyses uncovering that the poly- $C$ tract in the hypervariable region is a clonal marker (27). Similarly, Wang et al. reported mtMSI at high frequencies in the D-loop region of four common types of cancer in females, including endometrial, breast, cervical, and ovarian cancers (68).

In our study, $20 \%$ (8 out of 40 ) of the CNS patients were discovered to harbor mtMSIs. The frequency of $\mathrm{mtMSI}$ observed in our series is similar to the one reported in colorectal cancer by Lim et al. (37), but is lower than the one reported by other studies on the breast, gastric and endometrial cancers, which reported that $29.4 \%, 38.2 \%$, and $48.4 \%$, respectively, carried mtMSI, $(38,68)$. However, our frequency is higher than those reported by two previous studies by Lee et al. (32), and Fang et al. (10), in which squamous cell carcinomas of the lung (19\%) and hepatocellular carcinomas (12.2\%) were respectively investigated.

In our study, mtMSI was observed at only two loci, D310 and D16184 of the non-coding D-loop region. The D-loop region instabilities seem to be a frequent molecular abnormality detected in our group of brain tumor patients. In 2016, Yeung et al. examined the involvement of mitochondrial genome variants in a series of GBM cell lines using a combination of high-resolution melt analysis and next-generation sequencing. They revealed that the greatest frequency of mtDNA variants is in the D-loop and the origin of light strand replication in noncoding regions (70). Also, some researchers have reported a positive impact of the D-loop alterations in several other cancers. In the study of Venderbosch et al. in 182 metastatic colorectal cancer patients, $54.4 \%$ of the mtMSI were detected in the D-loop region (64). As previously stated, Wang et al. determined that mtMSI was frequently observed in the mitochondrial D-loop of endometrial (48.4\%), breast (29.4\%), cervical (25.4\%), and ovarian cancers (21.9\%) (68). Furthermore, Kleist et al. reported that the D-loop region had significantly more MSI in cases of the lymph node metastases (53.1\%) (28).

The D-loop region comprises essential replication and transcription elements that are responsible for the expression 
of the mitochondrial genome $(6,50)$. Sequence variants in this region can potentially affect mitochondrial biogenesis. This region consists of a triple-stranded DNA structure, which also acts as the connection point of mtDNA to the mitochondrial inner membrane. Moreover, the structure is constantly exposed to a high oxidative stress environment as the ROS is generated during oxidative phosphorylation (53). Consequently, the D-loop region of mtDNA is extremely susceptible to mutations by ROS-triggered damage $(50,53)$.

Insertions and deletions (indels) in the poly $\mathrm{C}$ stretch of the D-loop region were mostly present in this study. mtMSI (specifically in the D310 area) has now been targeted in several cancers $(3,8,30,38,41,60,63,69)$ since this region was first recognized 19 years ago by Sanchez-Cespedes et al. as a mutational hotspot (55). The D310 is a highly polymorphic region, located within the hypervariable II (HV II) region. This region is required for the formation of a firm RNA-DNA hybrid or an $\mathrm{R}$-loop to activate mtDNA replication. Therefore, it supports the view that this region contributes essentially to maintaining mitochondrial biogenesis and function (6). Additionally, the majority of indels related to the D310 region, which occur in some cancers, can lead to impaired of mitochondrial biogenesis (34). Since the first report published by SanchezCespedes's group, several teams have investigated D310 instability in various cancer types. For instance, in a study of several different solid tumors conducted by Geurts-Giele et al., they reported a D310 mutation frequency of $32 \%$ in colorectal, $19 \%$ in lung, $18 \%$ in head and neck, $16 \%$ in skin, $13 \%$ in breast and $11 \%$ in gynecological tumor samples (12).

The instability in the nucleotide positions 16184-16193 is another remarkable mutational hotspot in the mitochondrial $\mathrm{D}$-loop and has been extensively studied in several cancers $(3,8,10,17,28,30,39,41)$. The $16184-16193$ region is an unstable tract of poly cytosine residues and is prone to replication errors, most likely due to polymerase slippage. Instabilities in the nucleotides 16184-16193 are crucial to mtDNA due to their position on the 3 '-end of a terminationassociated sequence and at the 7S DNA binding site, which is pivotal to mtDNA synthesis modulation (39). Nevertheless, the elimination of the $T$ residue producing a long repeat of poly $\mathrm{C}$ stretch tends to be polymorphic, possibly resulting in instability $(12,15)$. These facts suggest that the sequence changes at this particular locus may contribute to the replication errors and mtDNA content alterations (39). A recent finding of Kim et al. showed a strikingly high frequency of mtMSI at D16184 in acute myeloid leukemia among Korean patients (70.3\%) (25). As observed in another study, the presence of poly $\mathrm{C}$ stretch alterations in D16184 locus has also been detected among gastric carcinoma (16.1\%) (17), and endometrial carcinoma patients (14.0\%) (41).

To our knowledge, the mechanisms underlying the occurrence of mitochondrial instability are still largely unexplored. One of the potential reasons is the faulty mtDNA mismatch repair system. mtDNA polymerase $\gamma(\mathrm{pol} \gamma)$ with proofreading exonuclease activity plays a dominant role in the DNA mismatch repair system and replication $(50,54)$. It was shown that mtDNA pol $\gamma$ is vulnerable to slippage, resulting in reduced proofreading efficiency $(23,43,49)$. mtDNA pol $\gamma$ is also believed to be a suspected target of oxidative damage that may hinder the fidelity of mtDNA repair and replication (14). The previous study proposed that the high frequency of mtMSI might be caused by a high rate of mitochondrial exposure to oxidative damage, hence initiating slippage errors of mtDNA pol $\gamma$ (54). The study by Habano et al. demonstrated that the mismatch repair system is crucial for mtDNA damage repair, thus, the malfunction of this system results in errors, which consequently increases the mutation rate (16).

Alterations in the mitochondrial genome may influence the mitochondrial function and regulation. Nonetheless, owing to the proximity of ROS source and the lack of protective histones, the accumulation of $\mathrm{MSI}$ may decrease the effectiveness of the mitochondrial respiratory chain, which is responsible for ROS production. Therefore, a defect in mitochondrial respiration might further increase ROS levels and cause an elevation in glucose-dependent metabolism $(18,29,51)$. Notably, this condition may lead to a high rate of mutation, eventually resulting in mitochondrial abnormalities. Furthermore, various mtDNA alterations and the associated mitochondrial dysfunction that may contribute to cancer progression have been hypothesized $(20,48,59)$.

It has been acknowledged that post-mitotic cells with a high demand for energy, especially muscle, heart, liver, and brain cells tend to have a greater number of mitochondria $(39,47)$. Moreover, cancer cells also require sufficient energy to support their uncontrolled rapid proliferation. Therefore, it is relevant that mtDNA alterations are often found at their certain levels in post-mitotic tissues as the clonal expansion of aberrations occurs within these cells over time. Wallace demonstrated high levels of clonally expanded mtDNA mutations in the brain and skeletal muscles (66). In addition, Kirches et al. observed a high prevalence of $\mathrm{mtMSI}$ in glioblastoma samples (88\%;15 out of 17) (26). These findings indicate that mutations in mtDNA might influence most areas, specifically the one comprising brain cells, which consequently give rise to mitochondrial diseases (47).

In our study, we concluded that there were no significant associations between MSI status and clinicopathological variables (age, sex, and histological type). Limited sample size and tumor types with very low heterogeneity included in this study may contribute to the lack of statistically significant different results. Of all brain tumors assessed, only $20 \%$ displayed MSI in our study. These results could be related to the sensitivity of the method used, which might influence the alteration rate detected. Perhaps the disadvantage of direct Sanger sequencing is its lower sensitivity than other methods. There is a need for further investigation using the so-called "gold standard" method or a combination of methods (such as capillary electrophoresis fragment analysis, next-generation sequencing) to enhance the limit of MSI detection in cancer (4).

The possible role of mtMSI in the process of tumorigenesis remains unclear, even though the hotspot areas for mtMSI have been widely recognized. However, it is believable that alterations in mtDNA might be selected during tumor 
development. Considering that a number of our patients harbored the D-loop $\mathrm{MSI}$, our findings may provide a clue that there is an essential role of mtDNA in MSI brain tumorigenesis. Moreover, this supports a hypothesis that alterations in mtDNA might be selected as a potential molecular biomarker for cancer detection (58).

\section{CONCLUSION}

The present preliminary results of this study propose a comparatively high frequency of $\mathrm{mtMSI}$ in brain tumors. Future larger sample size population-based studies are demanded to verify the findings and discover possible associations between the mtMSI and clinical parameters of patients with brain tumors. Therefore, the specific role and comprehensive molecular mechanisms of mtDNA alteration in brain tumor development and prognosis deserve further investigation.

\section{ACKNOWLEDGMENTS}

This study was financially supported by the University Sains Malaysia Research Fund [Research University Grant (RUi): 1001/PPSP/8012242].

\section{REFERENCES}

1. Anderson S, Bankier AT, Barrell BG, de Bruijn $\mathrm{MH}$, Coulson AR, Drouin J, Eperon IC, Nierlich DP, Roe BA, Sanger F, Schreier PH, Smith AJ, Staden R, Young IG: Sequence and organization of the human mitochondrial genome. Nature 290: 457-465, 1981

2. Andrews RM, Kubacka I, Chinnery PF, Lightowlers RN, Turnbull DM, Howell N: Reanalysis and revision of the Cambridge reference sequence for human mitochondrial DNA. Nat Genet 23:147, 1999

3. Ashtiani ZO, Heidari M, Hasheminasab SM, Ayati M, Rakhshani $\mathrm{N}$ : Mitochondrial D-Loop polymorphism and microsatellite instability in prostate cancer and benign hyperplasia patients. Asian Pacific J Cancer Prev 13:3863-3868, 2013

4. Baudrin LG, Deleuze JF, How-Kit A: Molecular and computational methods for the detection of microsatellite instability in cancer. Front Oncol 8:621, 2018

5. Boland CR, Thibodeau SN, Hamilton SR, Sidransky D, Eshleman JR, Burt RW, Meltzer SJ, Rodriguez-Bigas MA, Fodde R, Ranzani GN, Srivastava S: A National Cancer Institute Workshop on Microsatellite Instability for cancer detection and familial predisposition: Development of international criteria for the determination of microsatellite instability in colorectal cancer. Cancer Res 58:5248-5257, 1998

6. Clayton DA: Transcription and replication of mitochondrial DNA. Hum Reprod 15 Suppl 2:11-17, 2000

7. Crespo I, Vital AL, Gonzalez-Tablas M, Patino Mdel C, Otero A, Lopes MC, de Oliveira C, Domingues P, Orfao A, Tabernero MD: Molecular and genomic alterations in glioblastoma multiforme. Am J Pathol 185:1820-1833, 2015

8. Dai JG, Zhang ZY, Liu QX, Min JX: Mitochondrial genome microsatellite instability and copy number alteration in lung carcinomas. Asian Pac J Cancer Prev 14:2393-2399, 2013
9. Duraturo F, Liccardo R, Cavallo A, De Rosa M, Rossi GB, Izzo P: Multivariate analysis as a method for evaluating the pathogenicity of novel genetic MLH1 variants in patients with colorectal cancer and microsatellite instability. Int $\mathrm{J}$ Mol Med 36: 511-517, 2015

10. Fang DC, Fang L, Wang RQ, Yang SM: Nuclear and mitochondrial DNA microsatellite instability in hepatocellular carcinoma in Chinese. World J Gastroenterol 10:371-375, 2004

11. Genutis LK, Tomsic J, Bundschuh RA, Brock PL, Williams MD, Roychowdhury S, Reeser JW, Frankel WL, Alsomali M, Routbort MJ, Broaddus RR, Wakely PE Jr, Phay JE, Walker CJ, de la Chapelle A: Microsatellite instability occurs in a subset of follicular thyroid cancers. Thyroid 29:523-529, 2019

12. Geurts-Giele WRR, Gathier GHGK, Atmodimedjo PN, Dubbink HJ, Dinjens WNM: Mitochondrial D310 mutation as clonal marker for solid tumors. Virchows Arch 467:595-602, 2015

13. Goumard C, Desbois-Mouthon C, Wendum D, Calmel C, Merabtene F, Scatton O, Praz F: Low levels of microsatellite instability at simple repeated sequences commonly occur in human hepatocellular carcinoma. Cancer Genomics Proteomics 14:329-339, 2017

14. Graziewicz MA, Day BJ, Copeland WC: The mitochondrial DNA polymerase as a target of oxidative damage. Nucleic Acids Res 30:2817-2824, 2002

15. Ha PK, Tong BC, Westra WH, Sanchez-Cespedes M, Parrella P, Zahurak M, Sidransky D, Califano JA: Mitochondrial C-tract alteration in premalignant lesions of the head and neck: $A$ marker for progression and clonal proliferation. Clin Can Res 8:2260-2265, 2002

16. Habano W, Nakamura S, Sugai T: Microsatellite instability in the mitochondrial DNA of colorectal carcinomas: Evidence for mismatch repair systems in mitochondrial genome. Oncogene 17:1931-1937, 1998

17. Habano W, Sugai T, Nakamura SI, Uesugi N, Yoshida T, Sasou, S: Microsatellite instability and mutation of mitochondrial and nuclear DNA in gastric carcinoma. Gastroenterology 118:835841,2000

18. Hofhaus G, Attardi G: Efficient selection and characterization of mutants of a human cell line which are defective in mitochondrial DNA-encoded subunits of respiratory NADH dehydrogenase. Mol Cell Biol 15:964-974, 1995

19. Hung WY, Lin JC, Lee LM, Wu CW, Tseng LM, Yin PH, Chi CW, Lee HC: Tandem duplication/triplication correlated with polycytosine stretch variation in human mitochondrial DNA D-loop region. Mutagenesis 23:137-142, 2008

20. Hsu CC, Tseng LM, Lee HC: Role of mitochondrial dysfunction in cancer progression. Exp Biol Med 241:1281-1295, 2016

21. Johnson KJ, Schwartzbaum J, Kruchko C, Scheurer ME, Lau CC, Woehrer A, Hainfellner JA, Wiemels J: Brain tumor epidemiology in the era of precision medicine: The 2017 brain tumor epidemiology consortium meeting report. Clin Neuropathol 36:255-263, 2017

22. Kara M, Tatar A, Borekci B, Dagli F, Oztas S: Mitochondrial DNA 4977 bp deletion in chronic cervicitis and cervix cancers. Balkan J Med Genet 15:25-29, 2012

23. Kazak L, Reyes A, Holt IJ: Minimizing the damage: Repair pathways keep mitochondrial DNA intact. Nat Rev Mol Cell Biol 13:659-671, 2012 
24. Kelkar YD, Strubczewski N, Hile SE, Chiaromonte F, Eckert KA, Makova KD: What is a microsatellite: A computational and experimental definition based upon repeat mutational behavior at A/T and GT/AC repeats. Genome Biol Evol 2:620635, 2010

25. Kim HR, Kang MG, Lee YE, Na BR, Noh MS, Yang SH, Shin $\mathrm{JH}$, Shin MG: Spectrum of mitochondrial genome instability and implication of mitochondrial haplogroups in Korean patients with acute myeloid leukemia. Blood Res 53:240-249, 2018

26. Kirches E, Krause G, Warich-Kirches M, Weis S, Schneider T, Meyer-Puttlitz B, Marwin C, Dietzmann K: High frequency of mitochondrial DNA mutations in glioblastoma multiforme identified by direct sequence comparison to blood samples. Int J Cancer 93:534-538, 2001

27. Kirches E, Mawrin C, Schneider-Stock R, Krause G, Scherlach C, Dietzmann K: Mitochondrial DNA as a clonal tumor cell marker: Gliomatosis cerebri. J Neurooncol 61:1-5, 2003

28. Kleist B, Meurer T, Poetsch M: Mitochondrial DNA alteration in primary and metastatic colorectal cancer: Different frequency and association with selected clinicopathological and molecular markers. Tumor Biol 39:1010428317692246, 2017

29. Koppenol WH, Bounds PL, Dang CV: Otto Warburg's contributions to current concepts of cancer metabolism. Nat Rev Cancer 11:325-337, 2011

30. Kumimoto H, Yamane $Y$, Nishimoto $Y$, Fukami H, Shinoda M, Hatooka S, Ishizaki K: Frequent somatic mutations of mitochondrial DNA in esophageal squamous cell carcinoma. Int J Cancer 108:228-231, 2004

31. Lee J, Gwon G, Kim D: Mitochondrial D-loop polymorphism in tubular adenomas and serrated polyps of colorectal lesions. 10:1946-1953, 2017

32. Lee DH, Lee JH, Kim DK, Keum DY: Nuclear and mitochondrial DNAs microsatellite instability and mitochondrial DNA copy number in adenocarcinoma and squamous cell carcinoma of lung: A pilot study. APMIS 123:1048-1054, 2015

33. Lee JH, Kim DK: Microsatellite instability of nuclear and mitochondrial DNAs in gastric carcinogenesis. Asian Pac $J$ Cancer Prev 15:8029-8032, 2014

34. Legras A, Lie vre A, Bonaiti-Pelli C, Cottet C, Pariente A, Nalet B, Lafon J, Faivre J, Bonithon-Kopp C, Goasguen N, Penna C, Olschwang S, Laurent-Puig P: Mitochondrial D310 mutations in colorectal adenomas: An early but not causative genetic event during colorectal carcinogenesis. Int J Cancer 122:2242-2248, 2008

35. Li L, Chen L, Li J, Zhang W, Liao Y, Chen J, Sun Z: Correlational study on mitochondrial DNA mutations as potential risk factors in breast cancer. Oncotarget 7:31270-31283, 2016

36. Li T, Chen GL, Lan H, Mao L, Zeng B: Prevalence of the 4977bp and 4408-bp mitochondrial DNA deletions in mesenteric arteries from patients with colorectal cancer. Mitochondrial DNA A DNA Mapp Seq Anal 27:3774-3776, 2016

37. Lim SW, Kim HR, Kim HY, Huh JW, Kim YJ, Shin JH, Suh SP, Ryang DW, Kim HR, Shin MG: High-frequency minisatellite instability of the mitochondrial genome in colorectal cancer tissue associated with clinicopathological values. Int J Cancer 131:1332-1341, 2012
38. Ling XL, Fang DC, Wang RQ, Yang SM, Fang L: Mitochondrial microsatellite instability in gastric cancer and its precancerous lesions. World J Gastroenterol 10:800-803, 2004

39. Liou CW, Lin TK, Chen JB, Tiao MM, Weg SW, Chen SD, Chaung YC, Chuang JH, Wang PW: Association between a common mitochondrial DNA D-loop polycytosine variant and alteration of mitochondrial copy number in human peripheral blood cells. J Med Genet 47:723-728, 2010

40. Liu VWS, Shi HH, Cheung ANY, Chiu PM, Leung TW, Nagley P, Wong LC, Ngan HYS: High incidence of somatic mitochondrial DNA mutations in human ovarian carcinomas. Cancer Research 61:5998-6001, 2001

41. Liu VWS, Yang HJ, Wang Y, Tsang PCK, Cheung ANY, Chiu PM, Ng TY, Wong LC, Nagley P, Ngan HYS: High frequency of mitochondrial genome instability in human endometrial carcinomas. Br J Cancer 89:697-701, 2003

42. Loeb LA, Loeb KR, Anderson JP: Multiple mutations and cancer. Proc Natl Acad Sci USA 100:776-781, 2003

43. Longley MJ, Nguyen D, Kunkel TA, Copeland WC: The fidelity of human DNA polymerase $\gamma$ with and without exonucleolytic proofreading and the p55 accessory subunit. J Biol Chem 276:38555-38562, 2001

44. Máximo V, Soares P, Lima J, Cameselle-Teijeiro J, SobrinhoSimo, M: Mitochondrial DNA somatic mutations (point mutations and large deletions) and mitochondrial DNA variants in human thyroid pathology: A study with emphasis on hürthle cell tumors. American J Pathol 160:1857-1865, 2002

45. Mohamed Yusoff AA: Role of mitochondrial DNA mutations in brain tumors: A mini-review. J Can Res Ther 11:535-544, 2015

46. Mohamed Yusoff AA, Mohd Nasir KN, Haris K, Mohd Khair SZN, Abdul Ghani ARI, Idris Z, Abdullah JM: Detection of somatic mutations in the mitochondrial DNA control region D-loop in brain tumors: The first report in Malaysian patients. Oncol Lett 14:5179-5188, 2017

47. Mohamed Yusoff AA, Zulfakhar FN, Mohd Khair SZN, Wan Abdullah WS, Abdullah JM, Idris Z: Mitochondrial 10398A $>$ G $\mathrm{NADH}$-dehydrogenase subunit 3 of complex $\mathrm{i}$ is frequently altered in intra-axial brain tumors in Malaysia. Brain Tumor Res Treat 6:31-38, 2018

48. Moro L: Mitochondrial dysfunction in aging and cancer. J Clin Med 8: pii:E1983, 2019

49. Nakai T, Sakurada A, Endo T, Kobayashi H, Masuda S, Makishima $M$, Esumi $M$ : Caution for simple sequence repeat number variation in the mitochondrial DNA D-loop to determine cancer-specific variants. Oncol Lett 17:1883-1888, 2019

50. Nicholls TJ, Minczuk M: In D-loop: 40 years of mitochondrial 7S DNA: Exp Gerontol 56:175-181, 2014

51. Park JS, Sharma LK, Li H, Xiang R, Holstein D, Wu J, Leichleiter J, Naylor SL, Deng JJ, Lu J, Bai Y: A heteroplasmic, not homoplasmic, mitochondrial DNA mutation promotes tumorigenesis via alteration in reactive oxygen species generation and apoptosis. Hum Mol Gen 18:1578-1589, 2009

52. Parrella P, Seripa D, Matera MG, Rabitti C, Rinaldi M, Mazzarelli P, Gravina C, Gallucci M, Altomare V, Flammia G, Casalino B, Benedetti-Panici PL, Fazio VM: Mutations of the D310 mitochondrial mononucleotide repeat in primary tumors and cytological specimens. Cancer Lett 190:73-77, 2003 
53. Richard SM, Bailliet G, Pa'ez GL, Bianchi MS, Peltoma“ki P, Bianchi NO: Nuclear and mitochondrial genome instability in human breast cancer. Cancer Res 60:4231-4237, 2000

54. Richter C, Park JW, Ames BN: Normal oxidative damage to mitochondrial and nuclear DNA is extensive. Genetics 85: 6465-6467, 1988

55. Sanchez-Cespedes M, Parrella P, Nomoto S, Cohen D, Xiao Y, Esteller M, Jeronimo C, Jordan RCK, Nicol T, Koch WM, Schoenberg M, Mazzarelli P, Fazio VM, Sidransky D: Identification of a mononucleotide repeat as a major target for mitochondrial DNA alterations in human tumors. Cancer Res 61:7015-7019, 2001

56. Shahsiah R, Salarvand S, Miri R, Ghalehtaki R, Rakhshani $\mathrm{N}$ : The prevalence and associated factors of microsatellite instability in ovarian epithelial cancers detected by molecular genetic studies in a sample of Iranian women, Int $\mathrm{J}$ Cancer Manag 10:e11599, 2017

57. Sharma $H$, Singh A, Sharma $C$, Singh N: Mutations in the mitochondrial DNA D-loop region are frequent in cervical cancer. Cancer Cell Int 5:1-6, 2005

58. Shidara Y, Yamagata K, Kanamori T, Nakano K, Kwong JQ, Manfredi G, Oda H, Ohta S: Positive contribution of pathogenic mutations in the mitochondrial genome to the promotion of cancer by prevention from apoptosis. Cancer Res 65:16551663, 2005

59. Shin MK, Cheong JH: Mitochondria-centric bioenergetic characteristics in cancer stem-like cells. Arch Pharm Res 42:113-127, 2019

60. Tang M, Baez S, Pruyas M, Diaz A, Calvo A, Riquelme E, Wistuba II: Mitochondrial DNA mutation at the D310 (displacement loop) mononucleotide sequence in the pathogenesis of gallbladder carcinoma. Clin Cancer Res 10:1041-1046, 2004

61. Thibodeau SN, Bren G, Schaid D: Microsatellite instability in cancer of the proximal colon. Science 260:816-819, 1993
62. Tseng LM, Yin PH, Yang CW, Tsai YF, Hsu CY, Chi CW, Lee HC: Somatic mutations of the mitochondrial genome in human breast cancers. Gene Chromosome Can 50:800-811, 2011

63. Tyagi A, Pramanik R, Vishnubhatla S, Ali S, Bakhshi R, Chopra A, Singh A, Bakhshi S: Pattern of mitochondrial D-loop variations and their relation with mitochondrial encoded genes in pediatric acute myeloid leukemia. Mutat Res 810:1318,2018

64. Venderbosch S, van Vliet S, Craenmehr MH, Simmer F, de Haan AF, Punt CJ, Koopman M, Nagtegaal ID: Mitochondrial microsatellite instability in patients with metastatic colorectal cancer. Virchows Arch 466:495-502, 2015

65. Viana-Pereira M, Lee A, Popov S, Bax DA, Al-Sarraj S, Bridges LR, Stávale JN, Hargrave D, Jones C, Reis RM: Microsatellite instability in pediatric high grade glioma is associated with genomic profile and differential target gene inactivation. PLoS One 6:e20588, 2011

66. Wallace DC: Mitochondrial DNA sequence variation in human evolution and disease. Proc Nat Acad Sci 91:8739-8746, 1994

67. Wang L, Lv H, Ji P, Zhu X, Yuan H, Jin G, Dai J, Hu Z, Su $\mathrm{Y}, \mathrm{Ma} \mathrm{H}$ : Mitochondrial DNA copy number is associated with risk of head and neck squamous cell carcinoma in Chinese population. Cancer Med 7:2776-2782, 2018

68. Wang Y, Liu VW, Tsang PC, Chiu PM, Cheung AN, Khoo US, Nagley $\mathrm{P}$, Ngan HY: Microsatellite instability in mitochondrial genome of common female cancers. Int J Gynecol Cancer 16: 259-266, 2006

69. Wang Y, Liu VWS, Ngan HYS, Nagley P: Frequent occurrence of mitochondrial microsatellite instability in the d-loop region of human cancers. Ann NY Acad Sci 1042:123-129, 2005

70. Yeung KY, Dickinson A, Donoghue JF, Polekhina G, White SJ, Grammatopoulos DK, McKenzie M, Johns TG, St John JC: The identification of mitochondrial DNA variants in glioblastoma multiforme. Acta Neuropathol Commun 2:1, 2014 